\title{
Vestuário ergonômico para a prática de pole dance: 0 conforto térmico como requisito projetual
}

Ergonomic apparel for pole sports practicing: thermal comfort as a design requirement

BALDIN, Ana Elisa Contieri I Bacharel em Moda

Universidade Estadual de Maringá - UEM I anaelisa.b@hotmail.com

MENEGUCCI, Franciele I Mestre em Desenho Industrial

Universidade Estadual Paulista "Júlio de Mesquita Filho" -

UNESP I franciele_menegucci@yahoo.com.br

\begin{abstract}
Resumo
Esse artigo apresenta o processo de desenvolvimento de produtos de vestuário para praticantes do pole dance esportivo. Aborda os principais requisitos projetuais identificados por meio de pesquisa bibliográfica e de campo e apresenta a análise de dois produtos propostos a partir de adequações nos materiais têxteis e nos recursos construtivos.

\section{Abstract}

This paper presents the process of developing apparel products for pole sports practitioners. It addresses the main design requirements identified through literature and field research and presents the analysis of two products proposed from the adjustments in textile materials and building resources.
\end{abstract}

Palavras-chave: Pole Dance. Vestuário. Keywords: Pole Dance. Apparel. Ergonomics.

Ergonomia. 


\section{INTRODUC̣ÃO}

O Pole Dance é uma atividade que mistura dança e ginástica por meio de exercícios combinados em uma barra vertical, que requerem muita força, flexibilidade e resistência do corpo do atleta. Apesar de ter tido origem em casas noturnas na América do Norte, as dançarinas perceberam o potencial fitness nos movimentos complexos que realizavam. Na década de 1990 e nos anos 2000 as escolas especializadas começaram a surgir e a procura de pessoas em busca do mixde dança e musculação, que beneficia o corpo e eleva a autoestima, aumentou significativamente (CBPOLEDANCE, 2014).

Alessandra Rancan, atual campeã brasileira de Pole Dance, diz que a sustentação do corpo no pole ou barra de metal, além de se dar pela força, é exercida pelo atrito deste com a pele. Em contato com a barra, a pele não pode estar coberta por roupas nas pernas, braços e abdômen, para melhor aderir e evitar riscos, como escorregar (REDE VIDA, 2014).

$\mathrm{Na}$ área esportiva o atleta pode fazer do seu corpo uma extensão, se utilizando de uma vestimenta adequada, que é de extrema importância, pois caso isso não ocorra, a peça mal modelada pode impedi-lo de realizar movimentos necessários. Nesse caso, o vestuário destinado à prática diária de pole dance precisa atender algumas demandas específicas: permitir a aderência do corpo com a barra de metal, proporcionar trocas térmicas que diminuam a sudação e apresentar a flexibilidade necessária para a execução dos movimentos. Há ainda a necessidade de o vestuário agradar psicologicamente o indivíduo, pois ao mesmo tempo em que se precisa que este seja confortável e atenda as necessidades do público, as características estéticas são inerentes à este tipo de produto para que haja aceitação (GRAVE, 2004).

Conceitos ergonômicos aliados aos recursos construtivos de vestuário, bem como materiais têxteis adequados, apresentam-se como itens fundamentais para a compreensão da interação entre usuário, produto, tarefa e ambiente, que neste trabalho entende-se como usuário, vestuário e a barra de metal, a fim de desenvolver peças para o treino diário desta modalidade esportiva, para oferecer ao público um produto coerente com suas necessidades.

A partir desses pressupostos, esse artigo aborda o processo de desenvolvimento de produtos de vestuário para praticantes do pole dance esportivo. Trata-se de uma pesquisa exploratória, que objetiva expandir o conhecimento acerca do objeto de estudo e utiliza-se de métodos como o levantamento bibliográfico, que fornece suporte teórico para as análises e considerações, e pesquisa de campo, que propiciou maior familiaridade com as demandas que devem ser atendidas no desenvolvimento de produtos. 


\section{DESENVOLVIMENTO}

\subsection{A Evolução do Pole Dance}

O Pole Dance existe desde o século XII e sua origem está na prática do Mallakhamb, uma espécie de yoga praticada em cordas. A maneira como é conhecido hoje data dos anos de 1920, durante a Grande Depressão Americana, onde shows itinerantes tinham tendas paralelas à principal e uma delas possuía o show erótico das dançarinas HoochiCoochi, termo originado pelos movimentos que as dançarinas realizam com o quadril. As dançarinas se apresentavam em um pequeno palco, e devido ao espaço limitado começaram a se aproximar das barras de sustentação da tenda e dançar com elas. (PARIZZI, 2008).

O International Pole Dance Fitness Association(IPDFA) informa que pode haver conexões entre as dançarinas de dança do ventre e a "Dança dos setes véus" e o Pole Dance sensual. Outra influência apontada foi o parisiense Moulin Rouge, famosa por seus espetáculos noturnos, com sua arte inspirada na dança do ventre, e em danças como a rumba e o tango (IPDFA, 2014).

A prática foi se desenvolvendo nas tendas até chegar aos bares com estilo burlesquena década de 1950. Porém essa prática só começou a ser documentada na década de 1980 (PARIZZI, 2008), quando as dançarinas viram o potencial de fitness nos movimentos que realizavam. Na década de 1990 escolas especializadas começaram a surgir.

No Brasil, a prática se difundiu em 2007, após ser mostrado na novela Duas Caras, da Rede Globo de Televisão, onde a personagem Alzira, vivida pela atriz Flávia Alessandra, dançava pole dance em uma uisqueria. Em 2008 aconteceu o primeiro campeonato e, desde então, estes ocorrem com frequência. O Brasil também foi o primeiro da América do Sul a incluir a categoria masculina na modalidade e em 2011 a Federação Paulista de Pole Dance (FEPAPD) organizou o primeiro campeonato regional com apoio governamental, onde foi reconhecido como esporte (CBPOLEDANCE, 2014).

A divulgação desta atividade, bem como sua extensão ao esporte, ampliou a necessidade de oferta de produtos de vestuário que atendam às suas especificidades, visto que, os produtos de vestuário tradicionalmente utilizados em práticas esportivas podem não apresentar adequação à esta atividade, assim, entender as demandas ergonômicas pode propiciar o desenvolvimento de produtos com melhor desempenho. 


\subsection{Ergonomia Aplicada ao Vestuário}

A palavra ergonomia é derivada do grego ergon (trabalho) e nomos (regras), sendo que nos Estados Unidos é comum o uso do termo humanfactors (fatores humanos), e estuda várias situações como a postura, movimentos corporais, fatores ambientais, iluminação, entre outros, e é intrínseca a outras ciências como a antropometria, biomecânica, fisiologia, psicologia e desenho industrial (DUL; WEERDMEESTER, 2004).

De acordo com Martins (2008) a ergonomia se faz presente em qualquer objeto como utensílios domésticos, mobiliário e roupas, e considera os fatores físicos, fisiológicos, cognitivos, sociais e culturais. A autora ainda esclarece que o início de qualquer projeto ergonômico se dá pelo corpo humano, onde este é usado como escala de medidas considerando que tudo será adaptado para ele.

lida (2005) complementa dizendo que a ergonomia estuda a interação entre o homem, a máquina e o ambiente, onde a realização do trabalho se dá pelo modo como estes se relacionam, e assim é possível realizar adaptações para melhor desempenho da tarefa conforme a necessidade.

No desenvolvimento do vestuário, a adequação ergonômica pode ser obtida pela análise da tarefa a ser realizada, pelos recursos de modelagem inseridos e pelos materiais têxteis selecionados para sua construção, pois como afirma Saltzman (2008, p.306) "[...] o têxtil é a matéria que cobre e/ou descobre o corpo, participa de sua morfologia e gera uma nova relação entre o corpo e o meio".

\subsection{Modelagem e os Recursos para Construção do Vestuário}

Para confeccionar e vestir é imprescindível possuir conhecimentos acerca da anatomia humana e entender como o corpo funciona quando está em movimento, pois é isto que determinará como o tecido irá se ajustar nele (SANTOS, 2009).

As roupas não devem trazer desconforto ao usuário impedindo seus movimentos, pois o conforto é intrínseco ao seu bem estar. A combinação de boas técnicas de modelagem com materiais têxteis coerentes, assim como técnicas de confecção são de extrema importância para a obtenção de um produto final com qualidade. (SOUZA, 2006)

A modelagem deve sempre se adaptar ao material têxtil em que será confeccionado o produto, desta forma, por este trabalho buscar atender as necessidades das praticantes de um esporte, o uso de tecidos com elasticidade se faz coerente, pois permite ao corpo ter mais liberdade em se movimentar. Sendo assim, uma das técnicas da modelagem para tecidos elásticos é feita com base em moldes de tecido plano, onde sofrem uma redução percentual 
de acordo com o nível de elasticidade do material a ser modelado, para que quando vestido se acomode ao corpo perfeitamente. As curvas do modelo também podem ser reduzidas, mas ainda são necessárias para garantir conforto ao usuário. (DINIS; VASCONCELOS, 2009).

Para garantir o conforto e desempenho do usuário, Grave (2004) alerta que uma peça mal modelada, com tecido impróprio ou de tamanho inferior ao que usuário deveria usar pode causar deformações no corpo, assim uma peça muito apertada vestida por uma quantidade de tempo razoável pode ser responsável por alterações no tecido adiposo, alterando a forma original daquele local, além da possibilidade de prejudicar os movimentos, e consequentemente a autoestima.

Fischer (2010) aponta o uso de pences como recurso construtivo, pois estas controlam o excesso de tecido e auxiliam na criação da forma na roupa. As possibilidades na manipulação de pences são muitas, pois além de auxiliar na modelagem da peça trazem apelo estético, sendo possível transformá-las em pregas, franzidos ou apenas linhas decorativas.

Outro recurso interessante é a eliminação de costuras por meio de recortes, que acontece quando duas partes da modelagem são unidas para formar uma nova parte, respeitando o fio do tecido. Mas é preciso atentar-se, pois toda peça de roupa precisa de um mínimo de costuras para que seja feita, e é importante também verificar se este recurso não prejudicará seu caimento, ou se será necessário o uso de outros recursos em conjunto, como por exemplo, as pences, para que o modelo proposto dê certo (OSÓRIO, 2007).

Aliado aos recortes está a transferência de costura que visa, por meio da modelagem, inserir a costura em um local diferente do habitual e que possibilite maior conforto nos locais propostos. Outro fator interessante deste recurso é a possibilidade de mesclar tecidos, como neste caso, em que o tecido utilizado na lateral da peça é tecnológico, para proporcionar ao usuário melhor desempenho e conforto durante a prática esportiva (OSÓRIO, 2007).

\subsection{Conforto Térmico e o Vestuário: Efeito Chaminé}

Nas trocas de calor com o ambiente o corpo humano é capaz de se equilibrar termicamente. Por meio de fontes endógenas, está sempre produzindo e recebendo calor (IIDA, 2005). Grande parte da energia produzida pelo corpo é perdida em forma de calor e o restante é útil para a realização do trabalho e para manter as necessidades vitais. (GAMBRELL, 2002 apud CAMARGO; FURLAN, 2011).

lida (2005) indica que o Homem tem capacidade de tolerar diferentes climas, em virtude das glândulas sudoríparas, porém, dependendo da temperatura uma atividade pode se tornar ineficiente, pois está longe da zona 
de conforto do corpo, que o autor indica ser a temperatura interna de $35^{\circ} \mathrm{C}$, podendo variar em mais ou menos $2^{\circ} \mathrm{C}$, e se a termoregulação estiver diferente disso, há desconforto. Ressalta-se então a importância do uso de tecidos adequados para a troca de calor entre o corpo e o ambiente durante a prática de atividades físicas. Camargo (2007) salienta que a evaporação por meio do suor é a principal forma de troca de calor do corpo humano e que, quando não é suficientemente removido do corpo provoca desequilíbrio térmico e possível incômodo.

Desta forma, Zhang, Li e Wang (2012) escrevem que um importante aspecto para o conforto térmico é a possibilidade de diminuir ou controlar o calor por meio da evaporação do suor, porém, quando o corpo está coberto por roupas, esta eliminação é reduzida. Neste sentido, é introduzido o "efeito chaminé", que é utilizado como recurso para possibilitar a circulação do ar quente de dentro do vestuário para o exterior, assim são inseridas áreas de aberturas nas vestimentas para aumentar a ventilação melhorando o microclima que se forma entre o corpo e a roupa, quando o indivíduo está realizando uma atividade. Esse efeito ocorre, pois, quando ondas de calor ficam presas na área entre a pele e o tecido, estas procuram "buracos" para que possam sair.

Moran (1994) diz que o primeiro relato do "efeito chaminé" e início dos estudos se deu pela vestimenta do povo Inuít, que, por viverem em regiões árticas, frequentemente precisam escalar montanhas ou caçar comida, desta forma, durante o período de trabalho eles tinham que tolerar o calor que ficava preso em suas vestimentas à prova de vento e durante o descanso, o frio, juntamente com o suor acumulado. Sendo assim, desenvolveram peças de roupa com respiradouros, ou seja, algumas partes dessas peças foram fechadas com cordões e podem ser abertas quando o indivíduo desejar, pois assim o calor pode sair por essa abertura e deixar o corpo mais confortável e sem suor, e, nos períodos de descanso, as aberturas são fechadas, possibilitando o corpo de se reaquecer novamente, devido à impermeabilidade e proteção que suas roupas especiais são providas.

Para o desenvolvimento deste trabalho, se torna interessante unir os conceitos do "efeito chaminé", que evita o superaquecimento do corpo, juntamente com tecidos adequados à prática esportiva, pois Grave (2004, p.44) explica que "fibras e tecidos influenciam as atitudes do corpo", desta forma, o corpo do atleta será auxiliado na eliminação do suor e em sua termo regulação natural.

\subsection{Materiais Têxteis}

Sissons (2012) diz que a malha é formada por fios entrelaçados que podem ser de urdume ou trama. Na malharia de urdume é necessário o uso de diversas máquinas para sua construção e o uso de mais de um fio e resulta 
em um tecido com menor elasticidade, enquanto a feita por trama é apenas usado um fio contínuo, e o produto final possui maior elasticidade. Devido à sua construção, garante naturalmente maior troca de calor com o ambiente, pois as laçadas formam pequenos espaços de ar. A autora ainda reforça que a tecnologia é aliada a prática esportiva, pois, por meio dela, é possível desenvolver peças em malharia sem costura, ou com o mínimo desta.

Neste projeto, o uso de tecidos elásticos é coerente devido às suas características de permitir ao corpo melhores movimentos em comparação aos tecidos planos, sendo assim a malha apresenta-se como a melhor opção, por se tratar de um tecido que possui muita elasticidade e se adapta às formas do corpo humano como nenhum outro, é ideal para a construção de artigos esportivos. (SISSONS, 2012).

Considerando que o objetivo deste estudo é atender as necessidades corporais procedentesde uma prática esportiva, tecidos com fibras artificiais e sintéticas com aspectos tecnológicos são coerentes, devido aos benefícios que podem trazer, além deste aspecto, deve-se atentar para a estrutura dos materiais pois, como já citado anteriormente, estruturas mais abertas permitem melhor troca térmica com o ambiente.

Chataignier (2006) explica que na década de 1990, a empresa têxtil Rhodia lançou a microfibra, que além de ser considerado o primeiro tecido inteligente, por ter partículas que se uniam com o calor, ocasionando menor retenção de calor no corpo, também era prático, confortável e bonito, sendo bem aceito pelas mulheres da época.

A partir disto, os tecidos utilizados na indústria do vestuário esportivo começaram a ser intensamente pesquisados, e a Rhodia novamente inovou e desenvolveu a tecnologia dryfit ${ }^{\circledR}$, que faz troca térmica rapidamente com o meio externo, resultando em uma rápida secagem do tecido, quando exposto à transpiração ou qualquer situação em que este fique úmido ou molhado, ocasionando em maior conforto para o usuário. (CHATAIGNIER, 2006).

Pezzolo (2007) discorre sobre algumas fibras sintéticas, como é o caso do elastano, que foi registrada pela empresa têxtil DuPont com o nome comercial de Lycra ${ }^{\circledR}$. Esta fibra permite elasticidade por meio da mistura tanto em tecidos planos como em malharias, além de ser uma fibra que se adapta ao corpo sem prejudicar os movimentos, sendo então ideal para práticas esportivas. Outro aspecto importante do elastano é que seu uso se faz a partir de combinações com outas fibras, possibilitando diversas variações na composição de um tecido.

Há também a poliamida, que é leve, macia, não encolhe e nem deforma, é resistente ao uso, aos fungos e às traças, e sua característica mais marcante é que ela seca rapidamente, facilitando a transpiração corporal. Pode ser 
combinada com outras fibras, e seu uso é geralmente combinado ao elastano, pois juntos apresentam performance interessante para praticante de atividades que necessitem liberdade nos movimentos, assim como rápida troca de calor entre o corpo e o ambiente, ocasionando conforto térmico (PEZZOLO, 2007). O modal é também um excelente têxtil, fabricado a partir de fibras de madeira, e, sua principal característica é a grande absorção de suor e o toque macio, quase zero, sob a pele.

Outra tecnologia presente no mercado é a de compressão, que auxilia a prevenir possíveis dores que os atletas podem sentir durante ou depois do treino, isso é possível pois o tecido permite que as vibrações musculares sejam minimizadas, retardando a fadiga e evitando distensões e câimbras. (FALCÃO, 2010). Tais tecidos equilibram forte compressão e alta flexibilidade, que os atletas tanto necessitam. Também permitem troca térmica, pois, devido às texturas que tecidos compressores costumam ter, estes não ficam em contato direto com a pele, criando microclimas e auxiliando na secagem rápida do suor (SANTACONSTANCIA, 2011).

\subsection{Perfil do Público-alvo e Características de Produto}

Como pesquisa de campo, foi aplicado um questionário com 31 questões de múltipla escolha, aplicado de forma exclusivamente virtual no período de 24 de abril até 01 de maio de 2014, com 52 mulheres praticantes de pole dance entrevistadas. A análise dos resultados deste questionário possibilitou identificar o perfil dos usuários e as principais características necessárias aos produtos. A síntese dos resultados e análise das respostas são apresentadas na sequência.

Observou-se então que as praticantes pertencem a variadas faixas etárias, sendo que a maioria são jovens de 18 até 23 anos, e que, apesar de haver pessoas com mais de 40 anos praticando. Sobre a concentração deste público, a maioria vive nas regiões Sul e Sudeste e trabalha em diversos setores, não havendo concentração em apenas um. Também são mulheres que possuem boa renda familiar, sendo esta de até 10 salários mínimos.

Essas mulheres frequentam em sua maioria locais culturais e a cena noturna da cidade onde vivem, como também passam tempo significativo em academias, e escolheram praticar Pole Dance pois além desta prática proporcionar intenso exercício para o corpo humano, o esculpindo e o tonificando, é um diferencial pelo fato de aprenderem uma nova dança, desta forma, a maioria está feliz com o próprio corpo. A prática do Pole Dance acontece entre duas e três vezes por semana, sendo que cada treino dura em média uma hora, e, além desta atividade esportiva, praticam outros tipos de atividades, evidenciando a preocupação deste com a saúde e a boa forma corporal. 
De acordo com as respostas do mesmo questionário, percebe-se que as usuárias anseiam por peças adequadas para esta prática, pois estão constantemente adaptando peças de ginástica comuns para o Pole Dance, bem como por variedade de modelos neste segmento. Há também a extrema necessidade de que essas peças sejam confortáveis e com boa modelagem.

Acerca dos materiais têxteis, responderam que estes são imprescindíveis para que o desconforto causado pelo suor seja minimizado, pois é possível utilizar tecidos tecnológicos apropriados para o esporte com a devida elasticidade e que realizam rápida troca de calor entre corpo e ambiente.

Quanto à estética do produto foi notada preferência por dois grupos de cores, às escuras e as coloridas, principalmente com tons vibrantes, assim como a inserção de elementos que remetam à estética burlesqueque o Pole Dance historicamente possui, conferindo certa sensualidade às peças para o treino.

Desta forma, utilizando-se de meios construtivos e estéticos, as usuárias comprariam peças adequadas ao desempenho que necessita, e que valorize sua feminilidade durante um esporte, e pagariam até $R \$ 100,00$ por cada peça.

\subsection{Desenvolvimento e Análise dos Produtos}

Esse estudo é parte do desenvolvimento de uma coleção destinada a praticantes de pole dance da modalidade esportiva, assim, além dos recursos técnicos inseridos nos produtos, que são o foco deste artigo, foram utilizadas referências estéticas que nortearam o delineamento de formas, cores, texturas e demais atributos visuais do produto. Neste caso, a partir de preferências estéticas observadas na análise do questionário supracitado, selecionou-se como referência Dita Von Teese, a maior represente do burlesque no mundo, estilo que após suas inovações voltou aos holofotes com maior sofisticação e elegância, assim como o estilo vintage das pin-ups. Em meio aos encantos fantásticos e o espetáculo, a americana é conhecida pelos trajes deslumbrantes de alta costura cravejados de cristais Swarovski ${ }^{\circledR}$, bem como elementos de cena luxuosos e deslumbrantes, tornando Dita um ícone de beleza e moda para aqueles que admiram a cena burlesque atualmente, exaltando o poder e controle feminino acerca de seu próprio corpo. Todavia, ela não é apenas uma sensual e poderosa mulher, há nela uma delicadeza clássica, sendo ora uma femmefatale, ora uma romântica lady.

Na Figura 1 apresenta-se o desenho renderizado, no campo do design de moda denominado desenho fashion, e a representação técnica planificada de uma composição de dois produtos propostos para a prática do Pole Dance. A partir da pesquisa indicou-se o uso de dois tecidos, o Lumine $\|^{\circledR}$, composto por $57 \%$ modal, $39 \%$ poliamida e $4 \%$ elastanoe o Spine Lace ${ }^{\circledR}$, malha com 
alta elasticidade e secagem rápida devido a sua construção mais aberta que o comum, composto por $96 \%$ poliéster e $4 \%$ elastano, aplicado em locais estratégicos como as costas e as laterais do corpo, onde há maior sudação.

Figura 1 - Look 01

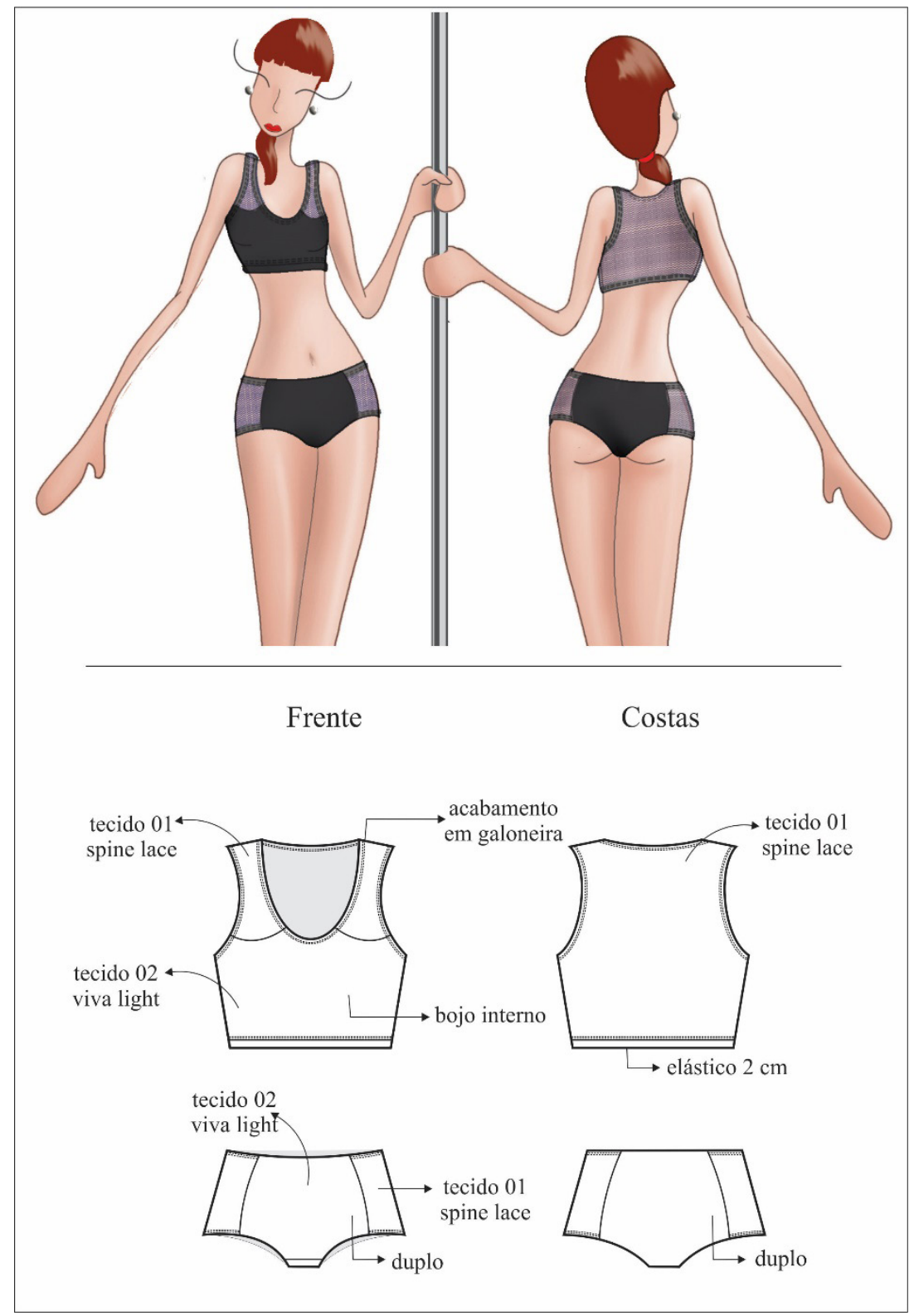

Fonte: Elaborado pelo autor, em pesquisa realizada (2014)

$\mathrm{Na}$ figura 02 , o produto proposto é um macaquinho, onde na região abaixo das axilas possui tecido estampado com tecnologia dryfit ${ }^{\circledR}$, composto por poliamida, a região do abdome e meio das costas também é confeccionado com esta mesma tecnologia. No busto, há o uso de suplex composto com $90 \%$ poliamida e $10 \%$ elastano, devido a sua capacidade de sustentação, e, nas laterais, microfibra splash com aspecto molhado e toque emborrachado por beneficiamentos têxteis, auxiliando na sustentação da atleta na barra de metal, este possui em sua composição $90 \%$ poliamida e 10\% elastano. 
Figura 2 - Look 02

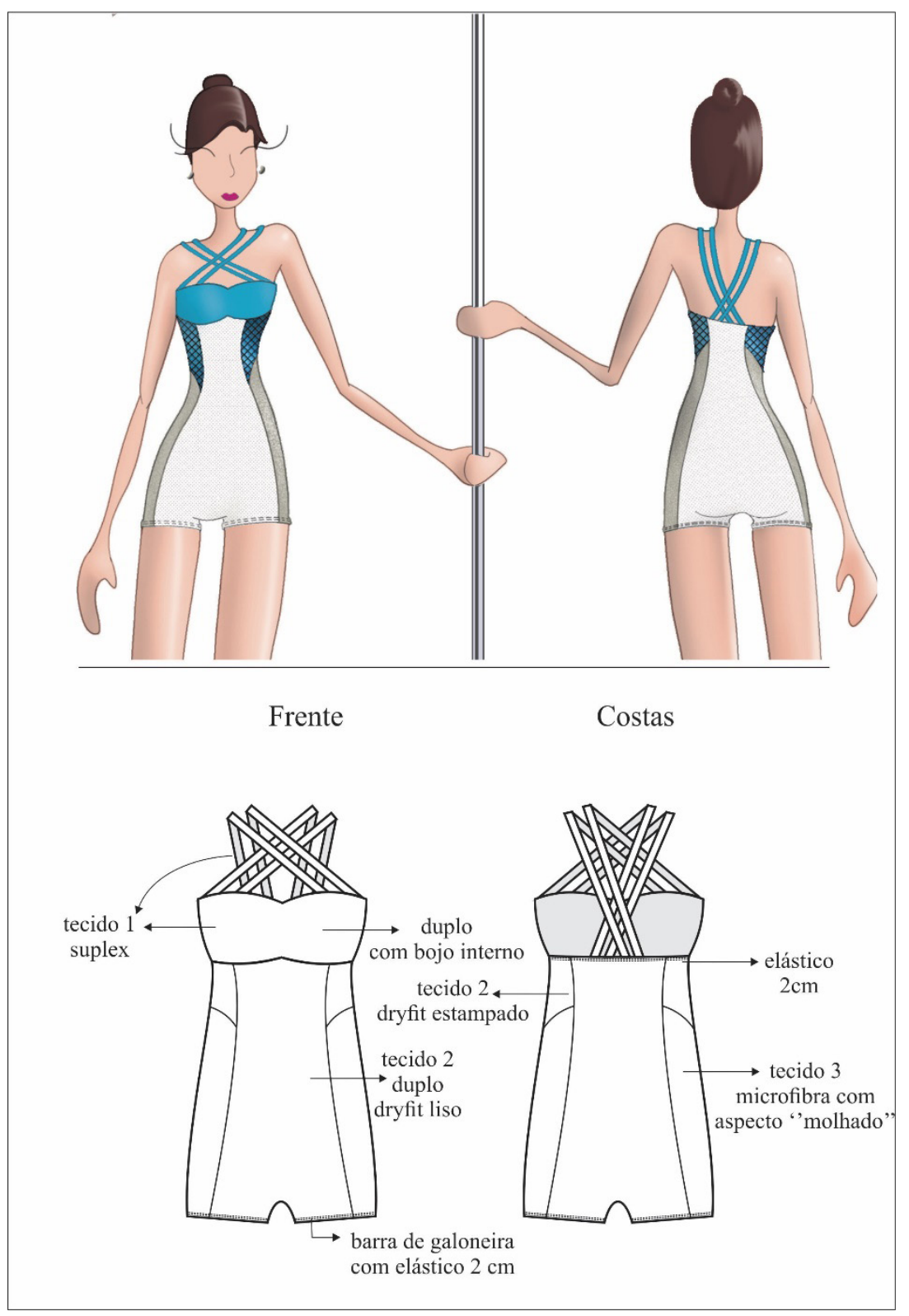

Fonte: Elaborado pelo autor, em pesquisa realizada (2014)

\section{CONCLUSÃO}

A mistura entre dança e ginástica que configura o Pole Dance proporciona força e flexibilidade aos praticantes e o aumento significativo de academias na última década, devido a necessidade em cuidar do corpo, fez com que o acesso a esta prática se tornasse maior, bem como a demanda por vestuário especializado.

Por se tratar de uma atividade física intensa, onde ocorre muita sudação e cansaço muscular no corpo do atleta, tecidos tecnológicos são necessários, especialmente os que realizam rápida troca térmica com o ambiente. Destacase também a utilidade de outros materiais, como o uso de tecidos com toque emborrachado, que auxiliam o usuário a ter maior estabilidade devido ao atrito com a barra de metal, oferecendo maior equilíbrio para ele durante a prática. 
Além dos materiais, observou-se que a modelagem adequada às formas anatômicas e as tarefas realizadas também é fundamental no projeto destes produtos. Assim, os recursos construtivos devem ser inseridos nas peças para facilitar a incorporação de tecidos específicos, melhorar a adaptação ao corpo e facilitar as atividades do usuário. Assim, observou-se que, para este tipo de produto, é imprescindível que a modelagem e os materiais sejam considerados de forma conjunta no projeto, pois é a partir destes recursos que torna-se possível obter o arrefecimento do calor e diminuição da sudação, como demostrado nas bibliografias consultadas.

Após essa fase de desenvolvimento de produtos exposta neste artigo, os produtos desenvolvidos deverão ser confeccionados e submetidos a avaliação por parte dos usuários, validando as proposições.

\section{REFERÊNCIAS}

CAMARGO, M. G. Análise da percepção térmica dos carteiros do CDD-Londrina em Relação ao uniforme utilizado em ambiente quente. 2007. 157 f. Dissertação (Mestrado em Desenho Industrial, Universidade Estadual Paulista, Bauru, 2007.

CAMARGO, M. G; FURLAN, M. Resposta fisiológica do corpo às temperaturas elevadas: Exercício, Extremos de temperatura e doenças térmicas. Revista Saúde e Pesquisa, Maringá, v. 4, n. 2, p. 278-288, maio/ago. 2011.

CBPOLEDANCE (Brasil). Campeonato Brasileiro de Pole Dance (Org). História: O início de tudo. 2014. Disponível em: <http://www.cbpoledance.com. br/\#!historia/c1u7o>. Acesso em: 1 mar. 2014

CHATAIGNIER, G. Fio a fio- tecido, moda e linguagem. São Paulo: Estação das letras, 2006.

DINIS, P. M.; VASCONCELOS, A. F. C. Modelagem. In: SABRÁ, Flávio. Modelagem tecnologia em produção de vestuário. São Paulo: Estação das Letras e Cores, 2009.

DUL, J; WEERDMEESTER, B. Ergonomia Prática. São Paulo: Edgard Blücher, 2004.

FALCÃO, J. O tecido certo para malhar. 2010. Disponível em: <http://vilamulher. com.br/moda/estilo-e-tendencias/o-tecido-certo-para-malhar-14-1-32-728. html>. Acesso em: 24 abr. 2014.

FISCHER, A. Construção de vestuário. Porto Alegre: Bookman, 2010. 
GRAVE, M. F. A modelagem sob a ótica da Ergonomia. São Paulo: Zennex, 2004.

IIDA, I. Ergonomia: Projeto e Produção. São Paulo: Blucher, 2005.

IPDFA. Historyof Pole. Disponível em: <http://www.ipdfa.com/about/historyof-pole/> Acesso em: 6 abr 2014.

MARTINS, Suzana Barreto. Ergonomia e moda: repensando a segunda pele. In: PIRES, D. B. Design de moda: olhares diversos. Barueri: Estação das Letras e Cores Editora, 2008.

MORAN, Emilio F. Adaptabilidade Humana. São Paulo: Edusp, 1994.

OSÓRIO, L. Modelagem: Organização e Técnicas de Interpretação. Caxias do Sul: Educs, 2007.

PARIZZI, L. Pole Dance Brasil - História do Pole Dance. 2008. Disponível em: <http://www.poledancebrasil.com.br/pole-dance-a-historia/>. Acesso em: 20 fev. 2014.

PEZZOLO, D. B. Tecidos: História, tramas, tipos e usos. São Paulo: Senac, São Paulo, 2007.

REDE VIDA. Conheça nossa bicampeã brasileira de Pole Dance. Programa Vida Melhor. Disponível: <http://www.youtube.com/watch?v=5iFY2kzO5mw>. Acesso em: 15 de fev. 2014.

SALTZMAN, A. O design vivo. In: PIRES, D. B. Design de moda: olhares diversos. Barueri: Estação das Letras e Cores Editora, 2008.

SANTACONSTANCIA. Compress ${ }^{\circledR}$. 2011. Disponível em: <http://www. santaconstancia.com.br/esportes/tecidos>. Acesso em: 7 out. 2014.

SANTOS, Cristiane de Souza dos. O corpo. In: SABRÁ, Flávio. Modelagem: tecnologia em produção de vestuário. São Paulo: Estação das Letras e Cores, 2009. Cap. 2.

SISSONS, Juliana. Malharia: Fundamentos de Design de Moda. Porto Alegre: Editoria Bookman, 2012. 
SOUZA, Patrícia de Mello. A modelagem tridimensional como implemento do processo de desenvolvimento do produto de moda. Bauru, 2006. Dissertação (Mestrado em Desenho Industrial) - Universidade Estadual Paulista.

ZHANG, X H; LI, A, J.; WANG, Y Y. Effects of clothing ventilation openings on thermoregulatory responses during exercise. Indian Journal Of Fibre\& Textile Research, Shanghai, v. 37, n. 2, p. 162-171. jun. 2012.

Submissão: 09-2016

Aceite: 10-2017 